Maciej Ciurej*

\title{
Supervising control system for oriented PV using weather forecasts
}

\begin{abstract}
This paper is devoted to the problem of controlling an oriented PV using weather forecasts. The described solution presents the use of fuzzy logic fundamentals in order to increase the efficiency of a PV system. It differs from most related papers in the fact that it uses fuzzy logic in order to process weather condition numeric values as input data. All of necessary steps to reproduce the proposed solution have been included.
\end{abstract}

Keywords: photovoltaic cell, fuzzy logic, weather forecast, supervising control, artificial intelligence

\section{Introduction}

Solar energy is the fourth-most-used source of renewable energy (right after hydropower, wind power, and biomass energy). Recent trends indicate its potential growth from $2.4 \%$ in 2015 to nearly $20 \%$ of the overall use of renewable energy by 2020 [3]. Despite the fact that it is the most generous source of energy due to its dispersion, it is not the most utilized one. The main issue for collecting energy via PV systems is the weather conditions. Each PV system is strictly dependent on the overall cloudiness or wind speed (for example), which can potentially affect the efficiency of such systems.

In this paper, a proposal for creating a supervisory control of oriented PV systems with the use of short-term weather forecasts is described.

The proposed solution is based on a single source of forecasts and implements a fuzzy controller in order to select the most suitable control algorithm for a PV system.

\section{Motivations}

As previously mentioned, weather strongly influences the work of PV systems when conditions change during the daylight hours. The energy effectiveness of PV systems have

^ AGH University of Science and Technology, Faculty of Electrical Engineering, Automatics, Computer Science and Biomedical Engineering, Krakow, Poland, e-mail: mciurej@agh.edu.pl 
been evaluated at between $19 \%$ to $35 \%$. In overcast conditions, it is possible to obtain a negative value of its energy effectiveness ratio (due to the energy consumed by PV systems while reorienting).

The implementation of a fuzzy controller to maximize the energy efficiency of a PV system was presented in [2]. An approach to a model PV system with fuzzy logic based on an MPPT algorithm was presented in [1]. The described solution presents a different approach to fuzzy logic usage. It is not used to improve the internal mechanism of PV work but rather to maximize the time of sun exposure and minimize the use of energy by the system itself.

The main motivation of this paper is to introduce short-term weather forecast with the use of a fuzzy logic-based algorithm in order to minimize the number of reorientation movements of a PV system as a means of reducing power consumption. This paper provides only the theoretical fundamentals for physical tests of the power consumption of the considered system. None of the tests have been described in this paper. Also, lower power consumption has not been proven in this paper.

The paper is organized as follows: first, elementary information about PV control and fuzzy control is recalled. Next, the proposed solution is presented with details. Finally, an example of the proposed system is presented.

\section{Preliminaries}

For the purpose of reorienting (re)orientable PV systems, there are four types of algorithms that can be applied [4].

- Time-based algorithm: reorients PV according to a specified trajectory depending on day of the year and geographic location. The priority is energy consumption.

- Storm algorithm: activated irrespective of factors other than strong wind. Priority is the offset time to horizontal position.

- Rain algorithm: sets PV into horizontal position (identical to the storm algorithm), but its priority is energy consumption.

- Sensor-based algorithm: applied to avoid cloudiness. The quality indicator describes both the energy consumption and reorienting time. It can be used when the collected information is not sufficient to choose one of the aforementioned algorithms.

A fuzzy controller can be described as a specified use case of fuzzy logic in order to compute the demanded control value. Constructing a fuzzy controller is comprised of three steps:

- create the membership function of the input,

- specify the fuzzy rule table,

- determine the procedure for defuzzyfing the result.

In the described solution, two inputs were determined: the value of the cloudiness and the wind speed value. The most common defuzzification algorithm is Mamdani's Center of 
Gravity method. In this paper, this method has been chosen due to its "democratic" character. In the Center of Gravity method, all active fuzzy rules participate in the defuzzification process. This guarantees sensitivity when changing its inputs.

The membership functions described later in this paper are based on the aforementioned values of the inputs. All algorithms besides the storm algorithm have determined membership functions. As previously mentioned, the storm algorithm only depends on the value of wind speed.

\section{Proposed solution}

In this section, the proposed solution is described. The proposed system can be treated as a composition of three modules:

- Forecast analytical module - extracts numerical data from the short-term forecast (stored in a png format file). More details in Subsection 4.1.

- Steering module for extracted data (supervising control algorithm for PV systems). More details in Subsection 4.2.

- Fuzzy Logic rules definition. More details in Subsection 4.3.

The general schema of the system architecture is presented in Figure 1.

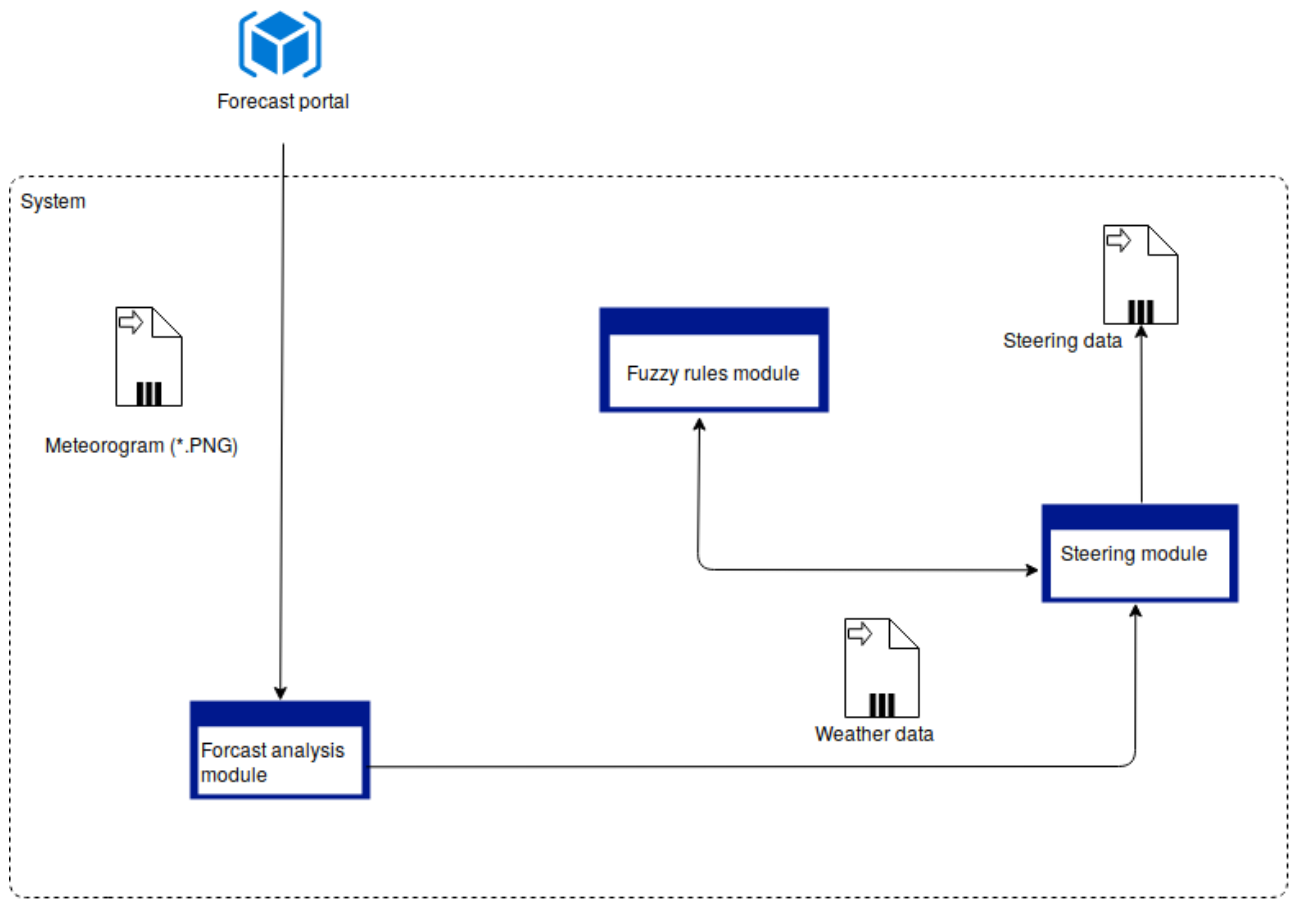

Fig. 1. System architecture 


\subsection{Forecast analytical module}

As a source of weather data, the numerical weather forecast of ICM Warsaw University (www.meteo.pl) has been applied. The author used only one model of forecast: Model UM, grid $4 \mathrm{~km}$, forecast length $60 \mathrm{~h}$. A caption for the example forecast is presented in Figure 2.

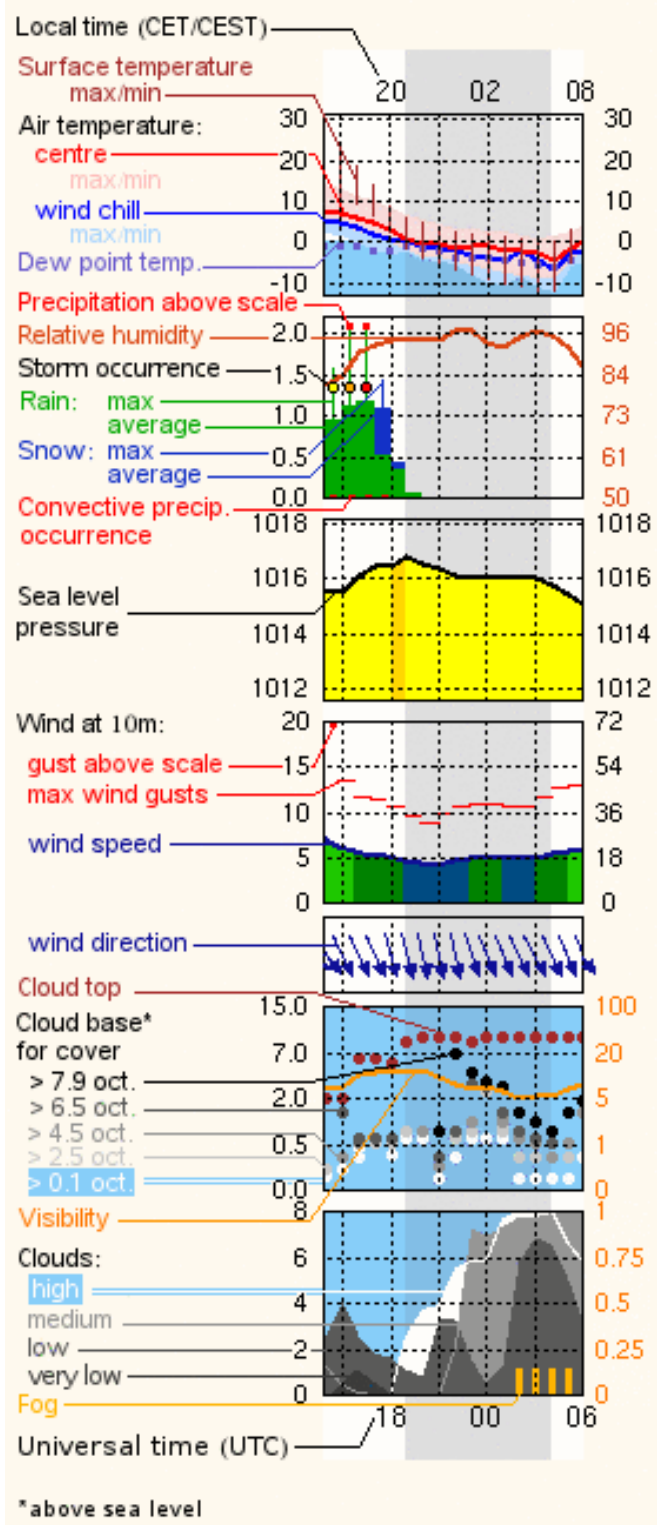

Fig. 2. Caption of forecast (source: www.meteo.pl) 
Only two sections of the forecast picture from the presented model are relevant for the proposed control strategy. These are:

- cloudiness (octas),

- wind speed $(\mathrm{km} / \mathrm{h})$.

\section{Numerical data extraction}

The extraction of numerical data is done by parsing the png file (pixel by pixel) using color recognition for the values of cloudiness and wind speed. The format of the output data has been composed as follows:

- timestamp (format: YYY-MM-DD HH:MM:SS),

- percentage of cloudiness of low clouds (0.01 precision),

- percentage of cloudiness of medium clouds (0.01 precision),

- percentage of cloudiness of high clouds (0.01 precision),

- average wind speed in $\mathrm{km} / \mathrm{h}(0.01$ precision $)$,

- maximum wind gusts in $\mathrm{km} / \mathrm{h}(0.01$ precision $)$.

An example row of the extracted data has the following form:

\section{7-09-01 00:08:44;1.28;73.1;62.8;1.54;3.33}

As can be observed, each value is separated with a semicolon. The collected data is stored in a CSV file and passed as an input argument for the supervising steering module. Implementation of the currently described module has been done with the use of Qt $\mathrm{C} / \mathrm{C}++$ development tools.

\subsection{Steering module}

The key responsibility of the steering module is to select a PV control algorithm suitable for execution during the forthcoming weather. A crucial element of this module is fuzzy logic rules. It requires normalized values of weather forecasts as input arguments (a more detailed description takes place in Subsection 3.3). Normalization takes place for two values from the forecast data file:

1) Cloudiness, with function:

$$
\operatorname{CloudNorm}(x)=\frac{(0.65 \cdot L(x))+(0.25 \cdot M(x))+(0.1 \cdot H(x))}{100}
$$

2) Wind speed, with function:

$$
\operatorname{WindNorm}(x)=\frac{\operatorname{AvgWind}(x)}{\operatorname{WindMax}}
$$


The explanations of formulas (1) and (2):

$x$ - stands for value of timestamp,

$L(x)$ - stands for percentage of cloudiness of low clouds,

$M(x)$ - stands for percentage of cloudiness of medium clouds,

$H(x)$ - stands for percentage of cloudiness of high clouds,

$\operatorname{Avg} \operatorname{Wind}(x)$ - stands for average wind speed,

WindMax - value is $20 \mathrm{~km} / \mathrm{h}$ as authoritary set maximum wind speed, which still will not degrade the PV system.

\subsection{Fuzzy rule module}

The concept of a Fuzzy Logic Controller (FLC) was introduced in [7] and brought the idea of a form control algorithm as a set of logical rules presented in the following form [8]:

$$
\text { IF } x \text { AND y THEN } z \text {. }
$$

In this paper, the Mamdani FLC has been applied. It can be described as a combination of four sequential steps applied in order to achieve the desired results [8]:

- fuzzification,

- rule evaluation,

- aggregation of rule outputs,

- defuzzification.

To implement the fuzzy controller, there is no need to have its model. The whole process of creation is based on defining the rules on how it should react (rules in the form of conditional statements) [5]. The fuzzy controller has been implemented in the MATLAB environment with the use of Fuzzy Logic Toolbox, which allows us to setup all characteristics for the controller [6]: gaussian membership functions, fuzzy logic rules, defuzzification method.

Both steering values (normalized wind speed and normalized cloudiness) need to have defined membership functions for their fuzzy states. For cloudiness, four states of intensity can be isolated:

- lack of clouds (sunny day),

- weak clouds,

- transparent sky cover,

- overcast.

Membership function for cloudiness is shown in Figure 3. 


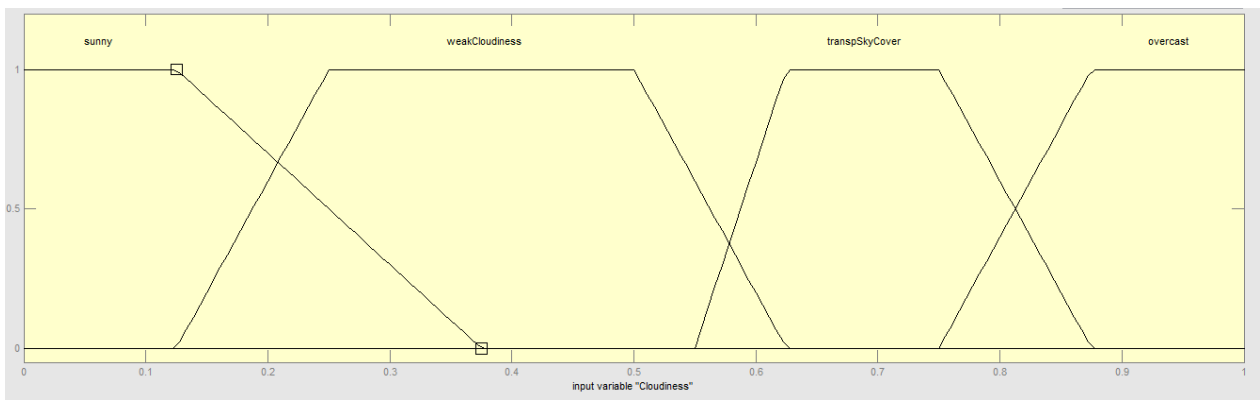

Fig. 3. Cloudiness membership function

For wind speed, three states of intensity can be isolated:

- weak,

- medium,

- strong.

The membership function for wind speed is shown in Figure 4.

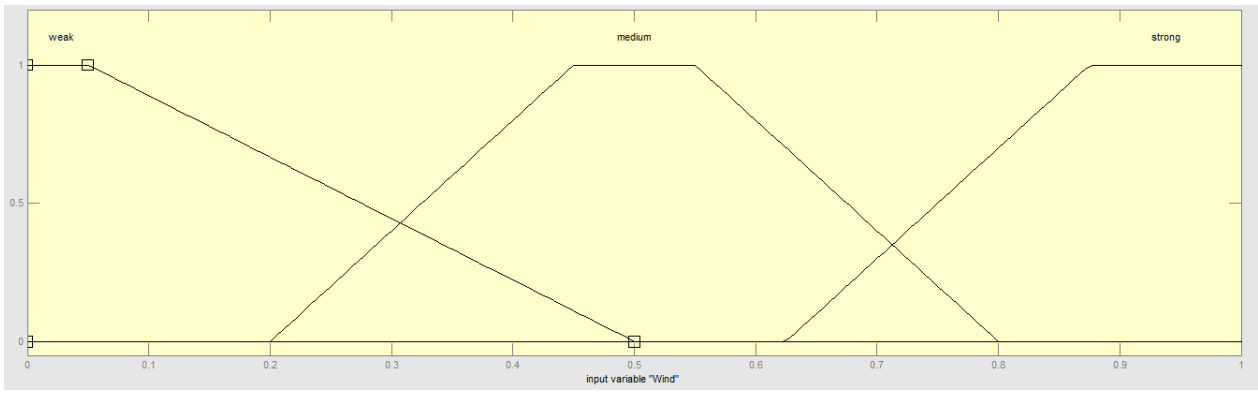

Fig. 4. Wind membership function

From the aforementioned, the storm algorithm triggering is bound only to wind speed, so it does not take part in specifying the membership function for the algorithms. The membership function for control is shown in Figure 5.

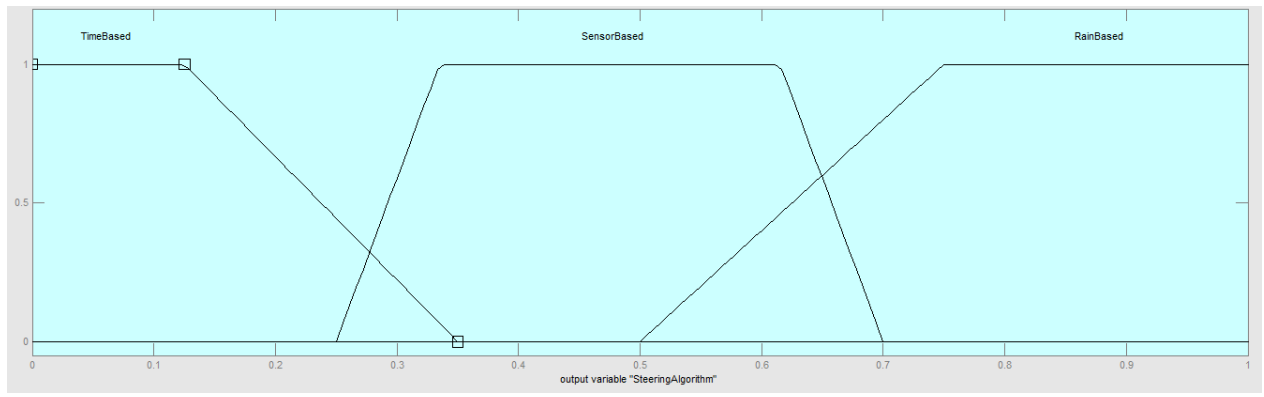

Fig. 5. Steering algorithm membership function 
As mentioned earlier, fuzzy rules are one part of a fuzzy controller. The rules used in this paper are given in Table 1 .

Table 1

Fuzzy rules

\begin{tabular}{|c|c|c|c|c|}
\hline No. & Wind & AND & Cloudiness & Algorithm \\
\hline 1 & Medium & AND & Sunny & Time based \\
\hline 2 & Medium & AND & Weak & Sensor based \\
\hline 3 & Medium & AND & Transparent cover & Sensor based \\
\hline 4 & Medium & AND & Overcast & Rain \\
\hline 5 & Weak & AND & Sunny & Time based \\
\hline 6 & Weak & AND & Weak & Time based \\
\hline 7 & Weak & AND & Transparent cover & Rain \\
\hline 8 & Weak & AND & Overcast & Rain \\
\hline 9 & Strong & - & - & Storm \\
\hline
\end{tabular}

The time-based algorithm has been indicated as the most suitable one in Rules 1, 5, and 6 . This type of algorithm has been chosen due to a cloudiness factor not being higher than the "Weak" value. The wind factor was also never higher than "Medium," which can indicate that the weather conditions are good enough to proceed with the time-based algorithm (which is natural for PV systems).

The sensor-based algorithm has been indicated as the most suitable one in Rules 2 and 3 . This type of algorithm has been chosen due to the "Medium" value of the wind and cloudiness factors not in the subset of extreme values ("Overcast," "Sunny"). The sensor-based algorithm is applied when weather conditions cannot be specified as conductive or unfavorable. In these cases, it is suggested to use the sensor-based algorithm in order to provide most accurate steering values.

The rain algorithm has been indicated as the most suitable one in Rules 4, 7, and 8. In the case of Rule 7, the rain algorithm has been chosen because of the "Weak" value of the wind factor - there is no strict indicator to use the sensor-based algorithm in order to reorient the PV system to commit potential danger to the physical elements of the system. In the case of Rules 4 and 8, the rain algorithm has been chosen due to the "Overcast" value of the cloudiness factor.

The defuzzed value is mapped into one of the three aforementioned algorithms with the use of the conditional expressions presented below:

- IF defuzzed value in [0, 0.3] THEN "Time-based" algorithm is implemented,

- IF defuzzed value in $(0.3,0.7]$ THEN "Sensor-based" algorithm is implemented,

- IF defuzzed value in $(0.7,1]$ THEN "Rain" algorithm is implemented,

- IF normalized wind value in $[0.8,1]$ THEN "Storm" algorithm is implemented. 


\section{Example of work}

In this section, the exemplary work of the proposed solution is given.

\subsection{Input and output data of system}

Figure 6 presents the weather forecast with a length of $60 \mathrm{~h}$, which was used as the example input of the described solution.

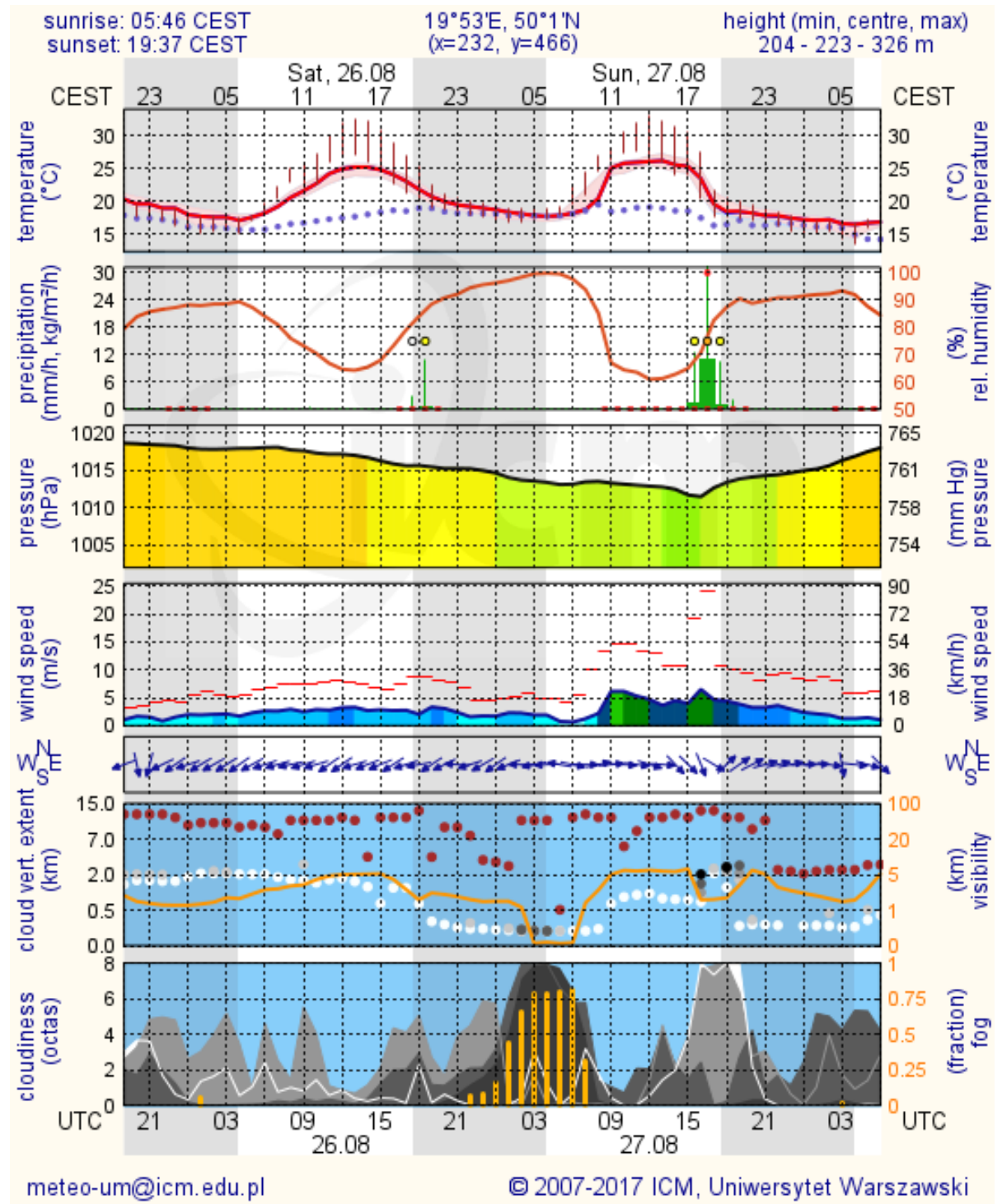

Fig. 6. Used forecast $60 \mathrm{~h}$ 
Results of the work of the proposed control algorithm are given in Table 2.

Table 2

Results of work

\begin{tabular}{|c|c|c|c|c|}
\hline Timestamp & Wind & Cloudiness & Deffuzed value & Algorithm \\
\hline 25-Aug-2017 18:08:44 & 0.091 & 0.2416 & 0.14257 & time \\
\hline 25-Aug-2017 19:01:08 & 0.0985 & 0.2523 & 0.14368 & time \\
\hline 25-Aug-2017 20:02:16 & 0.072 & 0.37245 & 0.13729 & time \\
\hline 25-Aug-2017 21:03:24 & 0.072 & 0.2756 & 0.14617 & time \\
\hline 25-Aug-2017 22:04:32 & 0.071 & 0.22626 & 0.14097 & time \\
\hline 25-Aug-2017 23:05:40 & 0.0775 & 0.12177 & 0.13092 & time \\
\hline 26-Aug-2017 00:06:48 & 0.069 & 0.13452 & 0.13207 & time \\
\hline 26-Aug-2017 01:07:56 & 0.039 & 0.16352 & 0.13477 & time \\
\hline 26-Aug-2017 02:09:04 & 0.1165 & 0.19227 & 0.13755 & time \\
\hline 26-Aug-2017 03:01:28 & 0.1165 & 0.19925 & 0.13826 & time \\
\hline 26-Aug-2017 04:02:36 & 0.1165 & 0.11923 & 0.1307 & time \\
\hline 26-Aug-2017 05:03:44 & 0.119 & 0.2155 & 0.13988 & time \\
\hline 26-Aug-2017 06:04:52 & 0.1165 & 0.1705 & 0.13543 & time \\
\hline 26-Aug-2017 07:06:00 & 0.1225 & 0.14175 & 0.13274 & time \\
\hline 26-Aug-2017 08:07:08 & 0.1765 & 0.24425 & 0.24548 & time \\
\hline 26-Aug-2017 09:08:16 & 0.1775 & 0.2155 & 0.18103 & time \\
\hline 26-Aug-2017 10:00:40 & 0.1775 & 0.1385 & 0.13299 & time \\
\hline 26-Aug-2017 11:01:48 & 0.1775 & 0.11283 & 0.13299 & time \\
\hline 26-Aug-2017 12:02:56 & 0.1775 & 0.1032 & 0.13299 & time \\
\hline 26-Aug-2017 13:04:04 & 0.2105 & 0.12242 & 0.13754 & time \\
\hline 26-Aug-2017 14:05:12 & 0.241 & 0.19798 & 0.13813 & time \\
\hline 26-Aug-2017 15:06:20 & 0.241 & 0.3221 & 0.338 & sensor \\
\hline 26-Aug-2017 16:07:28 & 0.235 & 0.34875 & 0.34173 & sensor \\
\hline 26-Aug-2017 16:59:52 & 0.2015 & 0.40935 & 0.3272 & sensor \\
\hline 26-Aug-2017 18:01:00 & 0.2015 & 0.3156 & 0.33836 & sensor \\
\hline 26-Aug-2017 19:02:08 & 0.2 & 0.2182 & 0.1879 & time \\
\hline 26-Aug-2017 20:03:16 & 0.166 & 0.2719 & 0.29298 & time \\
\hline 26-Aug-2017 21:04:24 & 0.2 & 0.355 & 0.33443 & sensor \\
\hline 26-Aug-2017 22:05:32 & 0.1945 & 0.39545 & 0.31685 & sensor \\
\hline
\end{tabular}


Table 2 (cont.)

\begin{tabular}{|c|c|c|c|c|}
\hline 26-Aug-2017 22:57:56 & 0.2 & 0.44785 & 0.32508 & sensor \\
\hline 26-Aug-2017 23:59:04 & 0.1435 & 0.45095 & 0.19949 & time \\
\hline 27-Aug-2017 01:00:12 & 0.0945 & 0.75125 & 0.16164 & time \\
\hline 27-Aug-2017 02:01:20 & 0.1 & 0.85135 & 0.5 & sensor \\
\hline 27-Aug-2017 03:02:28 & 0.103 & 0.85135 & 0.5 & sensor \\
\hline 27-Aug-2017 04:03:36 & 0.1215 & 0.1 & 0.12902 & time \\
\hline 27-Aug-2017 05:04:44 & 0.1215 & 0.1 & 0.12902 & time \\
\hline 27-Aug-2017 06:05:52 & 0.122 & 0.1 & 0.12902 & time \\
\hline 27-Aug-2017 06:58:16 & 0.0445 & 0.425 & 0.12859 & time \\
\hline 27-Aug-2017 07:59:24 & 0.024 & 0.17475 & 0.13584 & time \\
\hline 27-Aug-2017 09:00:32 & 0.15 & 0.14999 & 0.13349 & time \\
\hline 27-Aug-2017 10:01:40 & 0.251 & 0.14999 & 0.13349 & time \\
\hline 27-Aug-2017 11:02:48 & 0.3005 & 0.2417 & 0.24047 & time \\
\hline 27-Aug-2017 12:03:56 & 0.3005 & 0.21635 & 0.18321 & time \\
\hline 27-Aug-2017 13:05:04 & 0.3005 & 0.3665 & 0.39411 & sensor \\
\hline 27-Aug-2017 14:06:12 & 0.2555 & 0.23325 & 0.22306 & time \\
\hline 27-Aug-2017 14:58:36 & 0.249 & 0.30585 & 0.33725 & sensor \\
\hline 27-Aug-2017 15:59:44 & 0.249 & 0.464 & 0.3813 & sensor \\
\hline 27-Aug-2017 17:00:52 & 0.249 & 0.33725 & 0.34406 & sensor \\
\hline 27-Aug-2017 18:02:00 & 0.3435 & 0.334 & 0.36632 & sensor \\
\hline 27-Aug-2017 19:03:08 & 0.35 & 0.46365 & 0.45171 & sensor \\
\hline 27-Aug-2017 20:04:16 & 0.25 & 0.49375 & 0.38224 & sensor \\
\hline 27-Aug-2017 21:05:24 & 0.2445 & 0.19882 & 0.13821 & time \\
\hline 27-Aug-2017 22:06:32 & 0.2405 & 0.2367 & 0.23032 & time \\
\hline 27-Aug-2017 22:58:56 & 0.233 & 0.1951 & 0.13783 & time \\
\hline 28-Aug-2017 00:00:04 & 0.233 & 0.2783 & 0.30235 & sensor \\
\hline 28-Aug-2017 01:01:12 & 0.233 & 0.4863 & 0.36541 & sensor \\
\hline 28-Aug-2017 02:02:20 & 0.1985 & 0.51165 & 0.32293 & sensor \\
\hline 28-Aug-2017 03:03:28 & 0.1985 & 0.45315 & 0.32293 & sensor \\
\hline 28-Aug-2017 04:04:36 & 0.1985 & 0.5201 & 0.32293 & sensor \\
\hline 28-Aug-2017 05:05:44 & 0.1205 & 0.5082 & 0.12493 & time \\
\hline 28-Aug-2017 05:58:08 & 0.0985 & 0.43345 & 0.12732 & time \\
\hline
\end{tabular}


A graphical representation of the data included in Table 2 is presented in Figure 7.

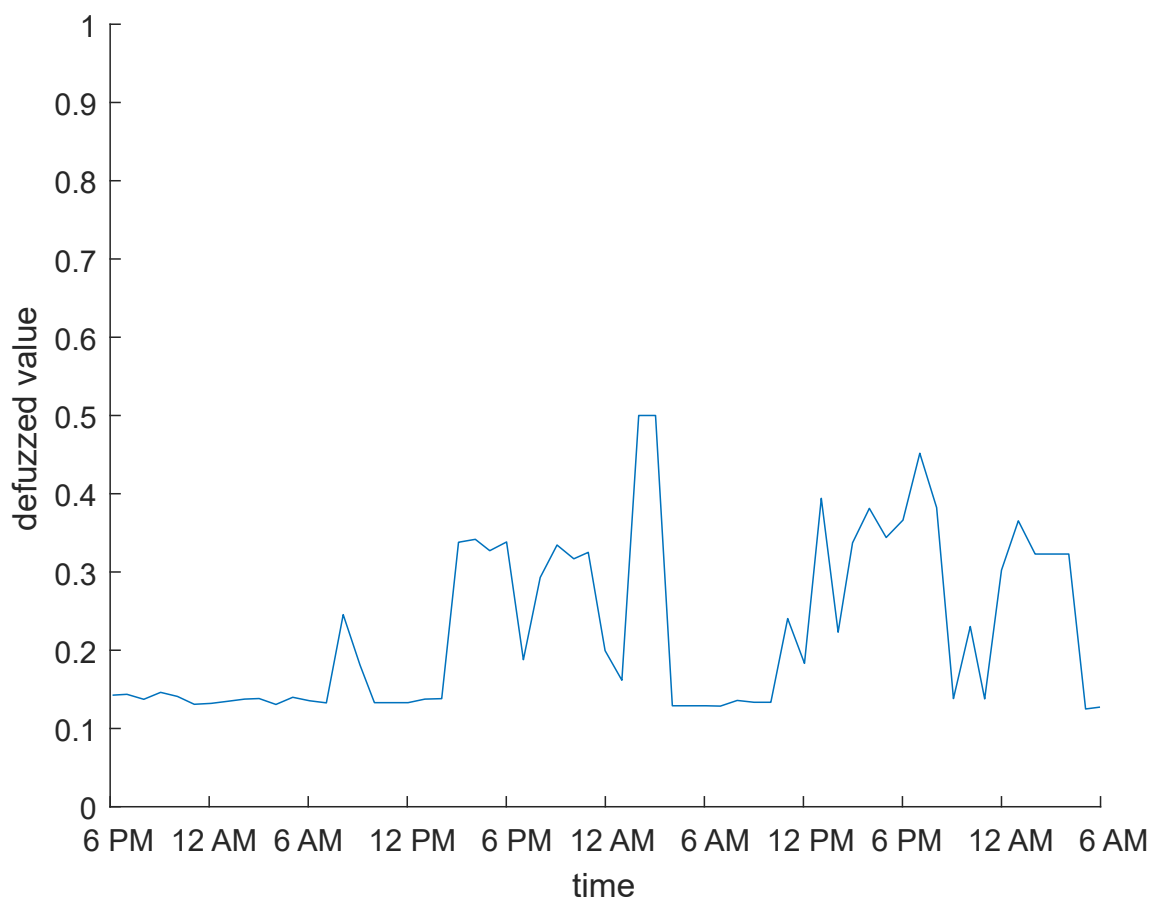

Fig. 7. Graphical representation of results

\section{Concluding remarks}

As can be observed, the timestamps where the system indicated the sensor algorithm are strongly correlated with the overcast intensity.

Output of the aforementioned system is only the first step into the complex analysis of the weather forecast. Despite the strong overcast conditions that were visually obvious to the human eye, the described system was not able to clearly indicate the storm algorithm but "only" the sensor-based one. As previously mentioned, the storm algorithm is triggered despite the fuzzy controller results (relying on wind speed).

The proposed solution can be extended in several ways:

- cover more than one source for forecasts,

- define more fuzzy logic rules in order to compute the steering algorithm more accurately,

- test more defuzzification methods than the one described.

The potential energy consumption difference was not presented in this paper. In the future evaluation of this paper, it is strongly recommended to take this indicator into consideration. 
When writing this paper, no other method for data retrieval from meteo.pl service was available. Potential further research of the presented matter can obtain data from the recently created API for this purpose (https://api.meteo.pl). However, model UM $60 \mathrm{~h}$ presented in this paper is not available in the aforementioned service.

\section{References}

[1] Mahamudul H., Saad M., Henk M.I., Photovoltaic System Modeling with Fuzzy Logic Based Maximum Power Point Tracking Algorithm, Hindawi Publishing Corporation International Journal of Photoenergy, 2013, http://dx.doi.org/10.1155/2013/762946.

[2] Bendib B., Krim F., Belmili H., Almi M.F., Boulouma S., Advanced Fuzzy MPPT Controller for a stand-alone PV system, The International Conference on Technologies and Materials for Renewable Energy, Environment and Sustainability, TMREES14.

[3] BP Statistical World Energy Review 2015, http://www.bp.com/en/global/corporate/about-bp/energyeconomics/statistical-review-of-world-energy.html (30.06.2015).

[4] Oprzędkiewicz K., Inteligentne sterowanie nadrzedne zespotem orientowanych ogniw stonecznych, XVIII Krajowa Konferencja Automatyki, Wrocław 08-10.09.2014.

[5] Piegat A., Modelowanie i sterowanie rozmyte, Akademicka Oficyna Wydawnicza EXIT, Warszawa 1999.

[6] MATLAB reference, Build Mamdani Systems (GUI), http://www.mathworks.com/help/fuzzy/ building-systems-with-fuzzy-logic-toolbox-software.html (01.07.2015).

[7] Zadeh L.A., Outline of a new approach to the analysis complex systems and decision processes, IEEE Transactions on Systems, Man, and Cybernetics, SMC-3(1), 1973, pp. 28-44.

[8] Iancu I., A Mamdani Type Fuzzy Logic Controller, in: Dadios E. (ed.), Fuzzy Logic. Controls, Concepts, Theories and Applications, InTech, 2012, pp. 325-350, available from: http://www.intechopen.com/books/fuzzy-logic-controls-concepts-theories-and-applications/amamdani-typefuzzy-logic-controller.

\section{Sterowanie nadrzędne orientowanymi ogniwami słonecznymi z wykorzystaniem prognoz pogody}

Streszczenie: Artykuł ten jest poświęcony tematyce opracowania sterowania nadrzędnego ogniw słonecznych, z wykorzystaniem prognoz pogody. Przedstawione w nim rozwiązanie korzysta z podstaw logiki rozmytej, aby zwiększyć wydajność energetyczną ogniw solarnych. W odróżnieniu od większośći prac o podobnej tematyce, wnioskowanie rozmyte służy przetworzeniu danych numerycznych uzyskanych z prognozy pogody. Wszystkie komponenty potrzebne do odtworzenia rozwiązania zostały opisane $\mathrm{w}$ artykule.

Słowa kluczowe: ogniwo słoneczne, logika rozmyta, prognoza pogody, sterowanie nadrzedne, sztuczna inteligencja 